\title{
0 apoio institucional como uma das faces da função apoio no Núcleo de Apoio à Saúde da Família (NASF):
}

\author{
para além das diretrizes
}

Renata Heller de Moura ${ }^{(a)}$

Cristina Amélia Luzio(b)

Moura $\mathrm{RH}$, Luzio CA. Institutional support as one of the faces of the support function in Family Health Support Centers (FHSCs): going beyond the guidelines. Interface (Botucatu). 2014; 18 Supl 1:957-70.

\begin{abstract}
The aim of this study was to add to the debate about Family Health Support Centers (FHSCs), starting from reflections about the support function. Support is generally presented, in official documents from the Ministry of Health and in academic-scientific publications, accompanied by descriptors that characterize it. Differences in terminology are commonly encountered:

"institutional support", "managerial support", "matrix support" and so on. With regard to FHSCs, published papers have highlighted the central role played by matrix support. However, we pose the question: what are the faces that the support function has been taking on in implementing such programs? To reflect on this and other issues, we developed a study of qualitative nature within a FHSC team in Paraná, outside of the state capital, using the methodological tools of participant observation, semi-structured interviews and discussion groups. We sought to demonstrate that the dynamics of the support function in FHSCs make it possible for both matrix support and institutional support to emerge.
\end{abstract}

Keywords: Institutional Support. Matrix support. Family Health Support Center. Primary Care. Public Health.
O propósito deste trabalho é incrementar o debate sobre o NASF, a partir de uma reflexão acerca da função apoio. A palavra apoio é, geralmente, apresentada, em documentos oficiais do Ministério da Saúde e em publicações acadêmicocientíficas, acompanhada por descritores que a caracterizam. É comum encontrarmos diferentes terminologias: "apoio institucional", "apoio à gestão", "apoio matricial". Quanto ao NASF, publicações examinadas destacam a centralidade do desempenho do apoio matricial. No entanto, nos perguntamos: quais as faces que a função apoio vem assumindo na implementação deste programa? Para refletir sobre essa e outras questões, desenvolvemos uma pesquisa de caráter qualitativo em uma equipe de NASF, no interior do Paraná, utilizando-nos das ferramentas metodológicas: observação participante, entrevista semiestruturada e grupos de discussão. Procuramos demonstrar que a dinâmica da função apoio no NASF permite a emergência tanto do apoio matricial quanto do apoio institucional.

Palavras-chave: Apoio institucional. Apoio matricial. Núcleo de Apoio à Saúde da Família. Atenção Primária à Saúde. Saúde Pública. (a) Departamento de Psicologia, Universidade Estadual de Maringá Avenida Colombo 5790, Bloco 118, Jd Universitário. Maringá PR, Brasil. 87020-900 rhmoura@uem.br

(b) Programa de Pós-Graduação em Psicologia, Faculdade de Ciências e Letras, UNESP - Univ. Estadual Paulista campus de Assis. Assis, SP, Brasil caluzio@assis.unesp.br 


\section{Introdução}

Nos últimos vinte anos, o Brasil tem passado por uma reestruturação bastante desafiadora no âmbito das políticas públicas de saúde. O Sistema Único de Saúde (SUS), nascido no bojo de uma luta mais ampla pela democratização do país, é portador de um consistente aparato jurídico-legal e teórico e, nos diversos cantos do país, acumulam-se experiências exitosas em sua implementação ${ }^{1,2}$.

Dentre os avanços notados, podemos citar: o aumento significativo do acesso aos cuidados de saúde ${ }^{(c)}$; a formalização da participação social, por meio dos Conselhos de Saúde, na criação de políticas e no controle de desempenho; a ampliação da abrangência e cobertura territorial realizada pela Estratégia da Saúde da Família(d) , desencadeando proporcional ampliação do investimento e expansão dos recursos humanos e de tecnologia em saúde.

No entanto, em um país de dimensões continentais como o nosso, marcado por amplas desigualdades regionais e econômico-sociais, o SUS continua enfrentando sérias dificuldades para garantir seus princípios mais fundantes: o acesso universal e equitativo e a atenção integral à saúde. De acordo com Oliveira ${ }^{3}$ :

O aumento das coberturas de acesso nem sempre significou, na mesma medida, o aumento de resolubilidade dos problemas de saúde nos diversos níveis de atenção. [...] Os serviços especializados e hospitalares, salvo algumas experiências focais, pouco se articulam com o restante da rede de serviços, persistindo modelos de gestão/ atenção que não coadunam com os princípios e diretrizes do SUS. Nos serviços de atenção básica as equipes de profissionais enfrentam grandes desafios cotidianos: compor-se e manejar-se como equipe; estabelecer uma nova relação com as atividades de acolhimento; discutir casos e implementar projetos terapêuticos que ampliem a clínica, produzindo sujeitos, autonomia e cidadania.

Dentre os desafios que atravancam o processo de implementação do SUS, precisamos ter em conta o arranjo complexo e peculiar da participação de organizações públicas e privadas, criando contradições, injusta competição e ideologias divergentes de modelos de atenção ${ }^{4}$. Além disso, enfrentamos o problema do subfinanciamento, que submete o SUS à supremacia de políticas neoliberais ao longo de sua história ${ }^{5}$, e à frouxa política orçamentária na determinação dos investimentos entre as três instâncias do governo.

Tendo em vista a necessidade de superar esses desafios e lacunas, mudanças recentes permitem vislumbrar o aparecimento de novos arranjos jurídico-legais, gerenciais e organizacionais, teóricos e técnico-assistenciais. A Política Nacional de Humanização (PNH), o Pacto pela Saúde ${ }^{(e)}$, a Política Nacional de Atenção Básica(f) (PNAB), o NASF6 6 , o Programa Nacional de Melhoria do Acesso e da Qualidade da Atenção Básica(g) $(\mathrm{PMAQ})$, a regulamentação da Emenda Constitucional $n^{\circ} 29^{(\mathrm{h})}$ são alguns aparatos que podemos mencionar como fruto da tentativa de superar essas lacunas.

Por mais que todos estes aparatos sejam legítimos e dignos de explicitação, neste trabalho queremos destacar o aparecimento da função apoio como um dos aparatos importantes para a construção de novos arranjos jurídico-legais, gerenciais e organizacionais, teóricos e técnico-assistenciais, visando contribuir com a expansão do SUS. Em alguns momentos de sua recente história, esta função aparece como fruto criativo do trabalho comprometido de atores do SUS, como no caso do Apoio Paidéia, sistematizado por $\mathrm{Campos}^{7}$, e do apoio institucional,

(c) "Na PNAD realizada em 1981, antes da criação do SUS, $8 \%$ da população (9,2 milhões de pessoas) afirmavam ter usado serviço de saúde nos últimos trinta dias, enquanto, em 2008, $14,2 \%$ da população (26.866.869 pessoas) relatavam uso

de serviços de saúde nos últimos 15 dias, o que representa um aumento de $174 \%$ no uso de serviços de saúde. O número de pessoas que busca a atenção básica aumentou cerca de $450 \%$ entre 1981 e 2008"1.

(d) De acordo com o Cadastro Nacional de Estabelecimentos de Saúde, o país conta, atualmente, com mais de

33.900 Equipes de

Saúde da Família, atendendo cerca de 103 milhões de pessoas em $82 \%$ (4.614) dos municípios brasileiros (Ministério da Saúde Sistema de Informação de Atenção Básica SIAB, março de 2013).

(e) Portaria $n^{\circ} 399$, de 22 de Fevereiro de 2006. Divulga o Pacto pela Saúde 2006 -

Consolidação do SUS, e aprova as Diretrizes

Operacionais do

Referido Pacto.

(f) Portaria $n^{\circ} 2488$, de 21 de outubro de 2011. Aprova a Política

Nacional de Atenção

Básica, estabelecendo a revisão de diretrizes e normas para a organização da Atenção Básica, para a Estratégia Saúde da Família e o Programa de Agentes Comunitários de Saúde.

(g) Portaria $\mathrm{n}^{\circ} 1654$, de 19 de julho de 2011. Institui, no âmbito do Sistema Único de Saúde, o Programa Nacional de Melhoria do Acesso e da Qualidade da Atenção Básica (PMAQ-AB) e o Incentivo Financeiro do $P M A Q-A B$, denominado Componente de Qualidade do Piso de Atenção Básica Variável PAB Variável. 
(h) No ano 2000, foi promulgada a Emenda $n^{\circ} 29$ para assegurar os recursos mínimos para o financiamento das ações e serviços públicos de saúde. Desde então, ela está em constante processo de debate. No ano de 2012, a Lei Complementar $\mathrm{n}^{\circ} 141$ de 13 de janeiro de 2012, veio para regulamentar a Emenda Constitucional $n^{\circ} 29$, de 2000. concebido pela PNH. Em outros momentos, ela aparece como função incorporada nas propostas oficiais do Ministério da Saúde (MS), tal como é o caso do apoio matricial e apoio à gestão, estabelecidos nas diretrizes do NASF e nas diretrizes orientadoras do Apoio Institucional Integrado.

Neste artigo, nos propomos a refletir sobre as faces da função apoio presentes no NASF. Colocamos, em diálogo, as diretrizes para a operacionalização desse dispositivo - apresentadas pelos documentos oficiais do MS - e uma experiência de pesquisa, que nos permitiu o acompanhamento dessa operacionalização em ato. Acreditamos em um SUS que dá certo e que a implementação de suas diretrizes e propostas possibilita a transformação e a produção coletiva de saúde para além do instituído, em defesa da vida. Embora as diretrizes do NASF apontem para a centralidade do apoio matricial no exercício da função apoio desenvolvida por esse programa, o apoio institucional no trabalho em ato do NASF também pode acontecer. Este é o ponto central de nossa reflexão e é dele que partem as discussões apresentadas neste texto. Buscamos pensar, portanto, sobre a contribuição do NASF no que tange à discussão dos processos de trabalho e da organização de serviços de saúde, ou seja, no que tange ao apoio institucional.

Esperamos que, com este trabalho, possamos incrementar o debate acerca da função apoio, buscando contribuir para suprir a necessidade de refletir sobre a operacionalização desta função em diferentes dispositivos do SUS, tal como sugerem os trabalhos de Fernandes ${ }^{8}$ Sampaio et al. ${ }^{9}$ e Oliveira $^{3}$.

\section{A função apoio e suas faces}

Etimologicamente, a palavra apoio tem origem no Latim ( $a d+$ podiu) e seu significado, de acordo com o dicionário etimológico ${ }^{10}$, está associado a: arrimo, base, esteio, fundamento, tudo que serve para amparar, firmar, segurar, sustentar, auxiliar, proteger, socorrer. Também está relacionado a argumento, autoridade, prova, ou qualquer coisa que se autorize, ou se prove, e a aprovação, o assentimento. O termo podiu era empregado, originalmente, na arquitetura romana para designar a base alta onde se elevavam os templos.

A utilização do termo apoio no contexto da saúde brasileira se deu nos anos 2000, aparecendo em textos de caráter teórico-técnicos e científico-acadêmicos, designando uma função ou uma metodologia de trabalho possível de ser desempenhada por um profissional ou por um grupo de profissionais da saúde. Alguns trabalhos recentes buscam tecer uma sistematização da função apoio no contexto da saúde e apresentam propostas de convenções terminológicas e conceituais $^{3,8}$. É comum encontrarmos, nos documentos oficiais do MS e em publicações acadêmico-científicas, a palavra apoio acompanhada por um descritor que a caracteriza em termos de modalidades distintas, tais como: "apoio institucional", "apoio à gestão", "apoio matricial".

Estamos propondo a utilização do termo "faces" da função apoio, em detrimento do uso dos termos "tipos" ou "modalidades", justamente porque entendemos que a operacionalização dessa função permite o aparecimento de faces diversas no exercício do apoio em ato, com alternância dessas faces, em diferentes intensidades, mas de maneira não excludente. Ou seja, o que queremos dizer é que a operacionalização do apoio matricial não exclui a operacionalização do apoio institucional ou do apoio à gestão... Se um dispositivo opera no sentido da implementação da função apoio matricial, por exemplo, outras faces podem ser mobilizadas, em conjunto e simultaneamente, em diferentes intensidades ou ênfases, e vice-versa. 
Um dos autores importantes para tomarmos como referência na sistematização do conceito e na apropriação do termo apoio para a área da saúde é Campos ${ }^{7,11}$. A partir de experiências que se iniciaram no município de Campinas, SP, Gastão Wagner de Souza Campos propõe o Apoio Paidéia. Segundo este autor,

O Conceito Apoio procura capturar todo este significado: não se trataria de comandar objetos sem experiência ou sem interesses, mas de articular os objetivos institucionais aos saberes e interesses dos trabalhadores e usuários. Tampouco se aposta somente nos recursos internos de cada equipe. O termo Apoio indica uma pressão de fora, implica trazer algo externo ao grupo que opera os processos de trabalho ou que recebem bens ou serviços. Quem apoia sustenta e empurra ao outro. Sendo, em decorrência, sustentado e empurrado por sua vez pela equipe "objeto" da intervenção. Tudo misturado e ao mesmo tempo. ${ }^{7}$

Esta é a concepção de apoio sustentada pelo Apoio Paidéia. É importante ter claro que o Apoio Paidéia não surge pronto e acabado, mas é resultado de experiências de trabalho vivo em ato, de reflexões teórico-metodológicas e da sistematização de novos aparatos conceituais. Buscando superar a lógica formal de produção taylorista incorporada na área da saúde, caracterizada pela fragmentação dos saberes e práticas, pela hierarquização dos serviços e pela dependência/supervalorização teórico-técnica do especialismo e expertise, Campos ${ }^{11}$ sistematiza o conceito de "Unidade de Produção".

Um primeiro passo na criação deste novo Método foi sugerir a modificação dos Organogramas dos serviços de saúde, em geral, inspirados no fayolismo e no taylorismo, criando 'Unidades de Produção'. Extinguir os antigos departamentos e seções recortadas segundo profissões, e criar outras Unidades mais conforme as lógicas específicas de cada processo de trabalho. Todos os profissionais envolvidos com um mesmo tipo de trabalho, com um determinado produto ou objetivo identificável, passariam a compor uma Unidade de Produção, ou seja, cada um destes novos departamentos ou serviços seriam compostos por uma Equipe multiprofissional. ${ }^{11}$

A unidade de produção permite a emergência das denominadas "Equipes de Referência" e "Equipes de Apoio". A equipe de referência é a menor unidade de poder em uma organização e sempre possui uma composição interdisciplinar.

A Equipe e os Profissionais de Referência são aqueles que têm a responsabilidade pela coordenação e condução de um caso individual, familiar ou comunitário. Objetiva ampliar as possibilidades de construção de vínculo entre profissionais e usuários. O termo "responsabilidade pela coordenação e condução" refere-se à tarefa de encarregar-se da atenção ao longo do tempo, ou seja, de maneira longitudinal, à semelhança do preconizado para equipes de saúde da família na atenção básica. ${ }^{12}$

A unidade de produção denominada de equipe de apoio surge da necessidade que a equipe de referência, por vezes, teria de receber o apoio matricial.

O Apoio Matricial em saúde objetiva assegurar retaguarda especializada a equipes e profissionais encarregados da atenção a problemas de saúde, de maneira personalizada e interativa. Opera com o conceito de núcleo e de campo. Assim: um especialista com determinado núcleo, apoia especialistas com outro núcleo de formação, objetivando a ampliação da eficácia de sua atuação. Trata-se de uma metodologia de trabalho complementar àquela prevista em sistemas hierarquizados, a saber: mecanismos de referência e contra-referência, protocolos e centros de regulação. ${ }^{12}$ 
Nesta nova lógica proposta por Campos e vivenciada em diferentes contextos e dispositivos de saúde (13; 14; 15), evidencia-se a indissolubilidade da atenção e da gestão, o que denota a emergência do apoio à gestão como uma face da função apoio também presente no Apoio Paidéia. O apoio se faz buscando superar a separação entre quem planeja e quem executa, incluindo a participação de gestores, trabalhadores e usuários na formulação, execução, avaliação do trabalho em saúde, promovendo gestão democrática do serviço. O apoio é, nesse sentido, um dispositivo de democratização. Sendo assim,

O Apoio Paidéia é uma postura metodológica que busca reformular os tradicionais mecanismos de gestão. Não se trata de uma proposta que busque suprimir outras funções gerenciais, mas de um modo complementar para realizar coordenação, planificação, supervisão avaliação do trabalho em equipe. ${ }^{7}$

Em 2004, a PNH publicou um documento orientador intitulado "HumanizaSUS: equipe de referência e apoio matricial", no qual é possível perceber a concordância entre as proposições feitas por Campos e as apresentadas pela PNH. Este documento problematiza o imperativo de se reformar e ampliar a clínica e as práticas de atenção no sentido da integralidade e, para tanto, aponta para a necessidade de se investir na mudança da estrutura assistencial e gerencial dos serviços de saúde.

É preciso criar novas formas de organização, novos arranjos organizacionais, capazes de produzir outra cultura e de lidar com a singularidade dos sujeitos. Esses novos arranjos devem ser transversais, no sentido de produzir e estimular padrões de relação que perpassem todos trabalhadores e usuários, favorecendo a troca de informações e a ampliação do compromisso dos profissionais com a produção de saúde. As equipes de referência e o apoio matricial são dois arranjos organizacionais que apresentam essas características de transversalidade. ${ }^{16}$

Portanto, a PNH é outra referência importante na sistematização e na incorporação da função apoio nas políticas públicas de saúde. Para a $\mathrm{PNH}$, apoio significa envolver/incluir todos os atores do trabalho em saúde na discussão-problematização dos modos de gestão das relações de trabalho e dos modos como ela se expressa. Pressupõe a defesa de um pressuposto essencial: a recusa de qualquer forma de tutela.

Apoiar, para $\mathrm{PNH}$, é estar junto com os diferentes sujeitos que constituem os sistemas de saúde - gestores, usuários e trabalhadores - discutindo e analisando os processos de trabalho e intervindo nas formas como os serviços estão organizados, potencializando aqueles que trabalham e utilizam os serviços como protagonistas e corresponsáveis pela produção de saúde, combatendo qualquer relação de tutela ou deslegitimação do outro. ${ }^{17}$

Vasconcelos e Morschel18 afirmam que "segundo as diretrizes propostas pela $\mathrm{PNH}$, apoio é uma função gerencial que reformula o modo tradicional de se fazer coordenação, planejamento, supervisão e avaliação em saúde". Como proposta para desfazer lógicas de hierarquização dos serviços e verticalização das decisões, a PNH lança mão do apoio institucional como estratégia metodológica que objetiva construir espaços de análise e interferência no cotidiano, potencializando análises coletivas de valores, saberes e fazeres. Busca, desse modo, implementar e mudar práticas. Segundo Mori e Oliveira ${ }^{19}$,

O apoio institucional é definido como acompanhamento qualificado do trabalho de equipes e tem, como característica principal, a oferta de estratégias metodológicas para implementação das diretrizes e dispositivos da Política. Ação de consultoria que coloca, em análise, os métodos de trabalho instituídos; incentiva trabalho cooperativo em equipe, de modo democrático, participativo e cogerido; estimula troca dos saberes, enfrentamento das disputas de poder, circulação de afetos, análise dos movimentos institucionais e criação de processos de trabalho que não distanciem as atividades da gestão e da atenção. 
Tais sistematizações são pensadas e emergem da realização do trabalho em ato (práxis), o que demonstra a possibilidade de emancipação dos sujeitos e transformação social por meio da produção coletiva da saúde. São movimentos considerados instituintes, pois instauram um movimento de enfrentamento diante dos desafios institucionais do SUS, buscando superar as lacunas apontadas incialmente neste texto.

A função de apoio institucional, conforme proposição de Passos, Neves e Benevides (2006), implica uma ação "entre", na interface entre produção de saúde e produção de subjetividade, entre análise das demandas e ofertas, entre as instituições de saúde e os movimentos que estranham seus funcionamentos, sejam eles movimentos sociais, analisadores sociais ou mesmo os movimentos sensíveis que operam aberturas e alteram os modos de sentir e perceber o mundo. Falamos, então, que o lugar do apoio funcionaria como um "não-lugar" (u-topos), já que ele se dá no movimento de coletivos, como suporte aos movimentos de mudança por eles deflagrados. ${ }^{20}$

Em 2006, a PNH fez um grande investimento no processo de formação de apoiadores institucionais e realizou o primeiro Curso Nacional de Formação de Apoiadores. O curso enfatizou a necessidade de uma ampliação da articulação em rede para sustentar a implementação da $\mathrm{PNH}$, bem como a ampliação do coletivo responsável por essa frente. Nos investimentos subsequentes, prevaleceu o princípio da descentralização, ficando os projetos e coordenação dos processos de formação a cargo das coordenações regionais em parcerias locorregionais. Colegiados gestores locais, regionais e estaduais foram criados para capilarizar esses novos arranjos. O Apoio Institucional foi incorporado como uma estratégia metodológica de ação privilegiada, atravessando tais colegiados que funcionaram como Unidades de Produção ${ }^{21}$.

As experiências exitosas que se acumularam por meio do Apoio Paidéia e do apoio institucional no âmbito da PNH acabaram por proporcionar a incorporação da função apoio em propostas oficiais do MS, tais como na criação do NASF e do Apoio Institucional Integrado.

Como este trabalho se propõe a focalizar as faces da função apoio no NASF, a seguir, um tópico inteiro será destinado a falar de sua sistematização. Portanto, passaremos agora para breves considerações sobre o Apoio Institucional Integrado.

O Apoio Institucional Integrado é uma recente estratégia metodológica proposta pelo MS para fortalecer a gestão do SUS, tendo em vista a implementação das políticas expressas no Plano Nacional de Saúde e nos dispositivos do Decreto $n^{\circ} 7.508 / 11^{(i)}$.

É nesse contexto entre a autonomia e a necessidade de interação entre os entes federados, entre as especificidades de cada Secretaria/ Política do MS e a necessidade de diminuir a fragmentação da agenda estratégica do SUS e a singularidades dos contextos locais - que se insere a discussão da estratégia do Apoio Integrado como forma de potencializar uma maior horizontalidade e cooperação nas relações interfederativas, construindo a regionalização e as redes de atenção, contratualizando o desenvolvimento de práticas de atenção e de gestão que produzam acolhimento com ampliação do acesso e da qualidade no SUS. ${ }^{22}$

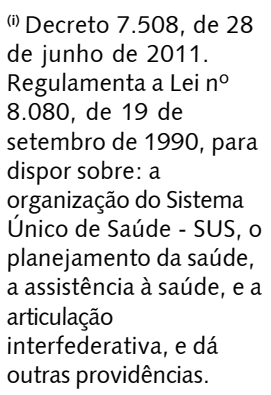


O Apoio Institucional Integrado incorpora as sistematizações da função apoio já apontadas anteriormente e possui tríplice tarefa: "ativar coletivos, conectar redes e incluir a multiplicidade de olhares e práticas, interesses e desejos para produção de objetivos comuns, ampliando a capacidade de tecer uma rede de compromissos, de contratualização entre sujeitos" ${ }^{22}$. Diante da recente formalização desta proposta, não encontramos publicações e relatos de experiências já realizados no país.

Nosso esforço até o momento não foi o de apresentar uma revisão sistemática da função apoio, mas o de recuperar um pouco de sua história e apresentar conceitos importantes que nos ajudarão a explicitar nosso entendimento de que a dinâmica da função apoio no NASF permite a emergência tanto do apoio matricial quanto do apoio institucional.

\section{NASF: um espaço para o exercício da função apoio}

O NASF foi criado em 2008, por meio da Portaria GM no 154. Este programa se insere dentro do escopo de ações da Atenção Básica (AB) em Saúde no Brasil e estabelece o credenciamento de equipes multiprofissionais, que assumem a função de apoiar a inserção da Estratégia de Saúde da Família na rede de serviços e ampliar a abrangência, a resolutividade, a territorialização e a regionalização das ações em saúde. Trata-se de um programa recente e ainda em construção e que, portanto, requer de nós, professores, pesquisadores, profissionais e usuários do SUS, um constante repensar sobre seu desenvolvimento nos diferentes municípios do país.

Os NASF não se constituem em porta de entrada do sistema e devem atuar de forma integrada à rede de serviços de saúde, a partir das demandas identificadas no trabalho conjunto com as Equipes de Saúde da Família (ESF). A responsabilização compartilhada entre as ESF e a equipe do NASF na comunidade prevê a revisão da prática do encaminhamento com base nos processos de referência e contrarreferência, ampliando-a para um processo de acompanhamento longitudinal de responsabilidade da equipe de Atenção Básica/Saúde da Família, atuando no fortalecimento de seus atributos e no papel de coordenação do cuidado no SUS. ${ }^{6}$

Acreditamos que o NASF nada mais é do que fruto do amadurecimento e institucionalização dos aparatos de unidades de produção, equipes de referência e equipes de apoio acima apresentados. Este excerto acima demonstra que a criação do NASF reforça a ideia de reformulação dos arranjos gerenciais e processos de trabalho em saúde, estabelecendo o próprio NASF como uma unidade de produção que funciona como equipe de apoio para fortalecer as equipes de referência (neste caso, as Equipes de Saúde da Família - ESF).

O NASF deve atuar dentro de algumas diretrizes relativas à $A B$, tais como: ação interdisciplinar e intersetorial; educação permanente em saúde dos profissionais e da população; desenvolvimento da noção de território; integralidade, participação social, educação popular; promoção da saúde e humanização. As áreas estratégicas sobre as quais as ações do NASF devem se realizar são: saúde da criança/do adolescente e do jovem; saúde mental; reabilitação/saúde integral da pessoa idosa; alimentação e nutrição; serviço social; saúde da mulher; assistência farmacêutica; atividade física e práticas corporais; práticas integrativas e complementares ${ }^{23}$.

A história do NASF é recente e o estabelecimento dessa proposta é um pouco controvertido, sobretudo no que diz respeito ao entendimento do que compete ao NASF. Para compreender este programa, faz-se necessário examinar alguns documentos do MS, tais como: a Portaria $n^{\circ} 154^{6}$, o Caderno de Diretrizes do NASF ${ }^{23}$ e a Oficina de Qualificação do NASF ${ }^{24}$.

Como já exposto acima, a Portaria no 154 estabelece a criação do NASF. Além disso, ela apresenta uma sistematização sucinta de suas diretrizes e determina a classificação dos NASFs em: NASF 1 e NASF 2. O NASF 1 pode ser composto por, no mínimo, cinco profissionais de nível superior de ocupações não coincidentes entre: médico acupunturista; assistente social; profissional da Educação Física; farmacêutico; fisioterapeuta; fonoaudiólogo; médico ginecologista; médico homeopata; nutricionista; médico pediatra; psicólogo; médico psiquiatra; e terapeuta ocupacional. O NASF 2 pode ser composto 
por, no mínimo, três profissionais de nível superior de ocupações não coincidentes entre: assistente social; profissional da Educação Física; farmacêutico;

fisioterapeuta; fonoaudiólogo; nutricionista; psicólogo; e terapeuta ocupacional.

Além disso, esta portaria também definiu: a quantidade de equipes que poderiam ser credenciadas (por número de habitantes e por número de ESF); a carga horária dos profissionais; o incentivo para o custeio de cada NASF; e um detalhamento de ações e responsabilidades dos profissionais do NASF.

Um dos pontos ${ }^{(j)}$ controversos da elementar Portaria $n^{\circ} 154$ diz respeito às competências e atribuições profissionais da equipe NASF. Só para citar alguns trabalhos, Fernandes ${ }^{8}$ e Sampaio et al. ${ }^{9}$ apresentam relatos de que não há clareza ainda quanto às especificidades do trabalho desses profissionais, muitas vezes transformando a retaguarda e o apoio em atenção especializada na atenção primária. Esta controvérsia se deu porque a lista de atribuições profissionais do NASF é grande e, dentre elas, uma ação citada é a de: "realizar atividades clínicas pertinentes a sua responsabilidade profissional" 6 . Isso abriu margem para alguns municípios interpretarem o NASF como uma possibilidade para se implantar uma espécie de centro de especialidades, com atuação de cunho ambulatorial, o que vai contra a ideia de criar novos arranjos gerenciais e de processos de trabalho em busca de uma produção mais coletiva da saúde.

O Caderno de Diretrizes do NASF, publicado em 2009, contribuiu para diminuir um pouco as dúvidas quanto aos processos de trabalho possíveis no NASF, ao afirmar que fazem parte dos processos de trabalho dessa equipe:

Intervenções específicas do profissional do Nasf com os usuários e/ ou famílias, com discussão e negociação a priori com os profissionais da equipe de SF responsáveis pelo caso, de forma que o atendimento individualizado pelo Nasf se dê apenas em situações extremamente necessárias e, quando ocorrer, continuar mantendo contato com a equipe de SF, que não se descomprometeria com o caso, ao contrário, procuraria redefinir um padrão de seguimento complementar e compatível ao cuidado oferecido pelo Nasf diretamente ao usuário, ou à família ou à comunidade. ${ }^{23}$

Além do Caderno de Diretrizes, a Oficina de Qualificação do NASF ${ }^{24}$ também reforma essa ideia. São documentos bastante semelhantes, e ambos fazem maior detalhamento da proposta do NASF e fundamentam melhor a concepção da função apoio que se pretende instituir por meio dele.

O correto entendimento da expressão "apoio", que é central na proposta dos Nasf, remete à compreensão de uma tecnologia de gestão denominada "apoio matricial", que se complementa com o processo de trabalho em "equipes de referência". [...] O apoio matricial será formado por um conjunto de profissionais que não têm, necessariamente, relação direta e cotidiana com o usuário, mas cujas tarefas serão de prestar apoio às equipes de referência (equipes de SF). ${ }^{23}$

Podemos perceber, portanto, que a função apoio no NASF está atrelada à face de apoio matricial. De acordo ainda com esses documentos do MS, o apoio matricial no NASF apresenta dupla função: suporte assistencial e técnicopedagógico. A dimensão assistencial é aquela que vai produzir ação clínica compartilhada para atendimento dos usuários, e a ação técnico-pedagógica vai

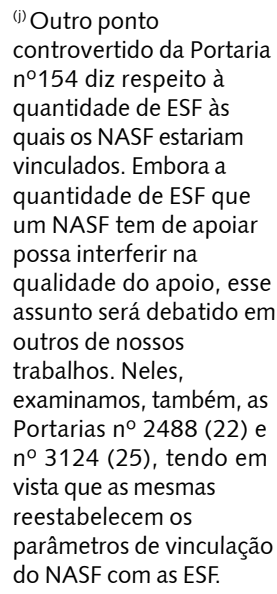


produzir ação de apoio educativo com e para a equipe. Essas duas dimensões podem e devem se misturar em diversos momentos.

Para a organização e o desenvolvimento do processo de trabalho do Nasf, algumas ferramentas tecnológicas podem ser enumeradas, seja de apoio à gestão, como a Pactuação do Apoio, seja de apoio à atenção, das quais são exemplos: o apoio matricial (descrito anteriormente), a Clínica Ampliada, o Projeto Terapêutico Singular (PTS) e o Projeto de Saúde no Território (PST). ${ }^{23}$

Assim sendo, resumidamente, temos que os processos de trabalho do NASF são: desenvolvimento de atendimento compartilhado, com intervenção interdisciplinar, com troca de saberes, capacitação e responsabilidade mútua; intervenções específicas dos profissionais do NASF com usuários e/ou famílias em situações especiais (conforme já mencionado acima); e ações comuns nos territórios de sua responsabilidade, desenvolvidas de forma articulada com as ESF, tais como o desenvolvimento do projeto de saúde no território, planejamento, apoio aos grupos, trabalhos educativos, entre outros. Como assinalamos acima, as funções de apoio mencionadas nos documentos examinados referem-se ao apoio à gestão e ao apoio matricial, entendendo-os como estratégias privilegiadas para o desenvolvimento de mudanças necessárias nos modos de gerenciamento e atenção em saúde.

Arranjos diversos, alguns exitosos, outros nem tanto, têm se estabelecido por meio da proposta NASF, no Brasil ${ }^{9,26,27 . ~ E x i s t e m ~ m i l ~ q u a t r o c e n t a s ~ e ~ d e z ~ e q u i p e s ~ d e ~}$ NASF registradas no Cadastro Nacional de Estabelecimentos de Saúde ${ }^{28}$. Destas, sete equipes de NASF estão instaladas em Maringá, PR, município no qual desenvolvemos nossa pesquisa, com o intuito de perceber, por meio do trabalho em ato, um arranjo possível para a implementação da proposta do NASF.

Este estudo integra uma ampla pesquisa de abordagem qualitativa realizada com um dos NASF de Maringá, em 2012/13(k). Para desenvolvê-la, fizemos uso das ferramentas metodológicas de: observação participante, entrevistas

${ }^{(k)}$ Esta pesquisa ainda está em curso. O trabalho de campo foi concluído em julho de 2013, porém a análise e sistematização dos dados continuam em andamento. semiestruturadas e grupos de discussão, realizados com gestores, profissionais do NASF e profissionais das equipes de referência para as quais este NASF desenvolve a função de apoio. A pesquisa foi devidamente submetida à Plataforma Brasil e aprovada pelo Comitê de Ética em Pesquisa da UNESP/Assis.

O recorte apresentado na forma deste artigo, procura discutir as faces que a função apoio vem assumindo na implementação deste programa. É sobre este ponto que nos concentramos a seguir.

\section{Apoio Institucional no NASF: uma possibilidade}

Maringá é o terceiro maior município do Paraná, com aproximadamente trezentos e sessenta mil habitantes. Tem um IDH elevado de 0,841 e o $68^{\circ} \mathrm{PIB}$ do país $(R \$ 8.263 .628,00)^{29}$. 95,1\% das pessoas são alfabetizadas e 98,4\% da população vivem na área urbana. É a $7^{\mathrm{a}}$ cidade com melhor saneamento básico do Brasil. Possui $95 \%$ de cobertura de esgoto e $100 \%$ do esgoto é tratado ${ }^{30}$. A cidade está subdividida em zonas fiscais, começando pela Zona 01 (onde fica localizado o Centro Financeiro da cidade) e terminando na Zona 50, além de bairros, loteamentos e dois distritos (Floriano e Iguatemi). As zonas fiscais têm função meramente administrativa.

A Estratégia Saúde da Família foi implantada no município de Maringá em 1999, inicialmente com sete equipes. Atualmente, existem 64 ESF, distribuídas nas 
29 Unidades Básicas de Saúde (UBS), que atendem 74.666 famílias, com uma cobertura de, aproximadamente, $80 \%{ }^{28}$.

O NASF foi implantado em Maringá no ano de 2009, com o credenciamento de sete equipes, sendo que este número permanece o mesmo atualmente. A entrevista realizada com a coordenadora dos NASF de Maringá deixou claro que a implementação do mesmo nesse município se deu por meio de um processo de estudo e diálogo, realizado por uma comissão de gestores da Secretaria Municipal de Saúde que, segundo ela, envolvia: a gerência da Assistência em Saúde, da Atenção Básica, algumas categorias profissionais e representantes da Universidade Estadual de Maringá (UEM).

A comissão, entre outros assuntos, colocou em discussão três questões centrais: quantas equipes de NASF seriam implantadas? Quais categorias de profissionais iriam compor esses núcleos? E a qual UBS elas estariam vinculadas?

A comissão decidiu por implementar sete NASF na modalidade 1, proporcionando vinculação com todas as ESF existentes em seu território, numa média de nove ESF para cada NASF. Além disso, a comissão refletiu sobre os indicadores e necessidade municipais de saúde e, a partir disso, definiu as categorias profissionais: psicólogos, educadores físicos, nutricionistas, farmacêuticos, assistentes sociais, fonoaudiólogos, terapeutas ocupacionais e fisioterapeutas. O arranjo de profissionais para cada NASF, dentre essas categorias, foi realizado posteriormente, pela pactuação com as equipes de referência, ou seja, com as ESF.

O NASF pesquisado ${ }^{(1)}$ conta com os seguintes profissionais: uma assistente social, uma educadora física, duas nutricionistas, uma psicóloga e dois terapeutas ocupacionais. Esta equipe está vinculada a nove ESF, distribuídas em três UBS.

A observação participante permitiu que as pesquisadoras acompanhassem várias ações desenvolvidas pela equipe. A seguir, apresentamos uma breve sistematização das faces da função apoio verificadas e extraídas do diário de campo das pesquisadoras:

1) Participação das reuniões das equipes de referência, ou seja, das ESF. Cada ESF realiza reuniões semanalmente. O NASF sempre envia de três a quatro representantes para estarem presentes nestas reuniões. Nelas verificamos a realização apoio matricial, com a discussão de casos e situações relacionadas aos usuários e familiares, com compartilhamento da clínica e realização de Projeto Terapêutico Singular. Nelas, percebemos, também, a realização de Projetos de Saúde no Território e apoio à gestão. As pesquisadoras tiveram a oportunidade de presenciar a elaboração dos Planos Anuais de Saúde para 2013. Estes foram pactuados pelas equipes de referência, com apoio do NASF, e este, por sua vez, recebeu orientações da gestão central da Secretaria de Saúde, para discutir a pactuação de alguns indicadores com cada ESF.

2) Participação das reuniões gerais das UBS. Cada UBS realiza reuniões periódicas mensais ou bimestrais (conforme necessidade). O NASF contribui para a organização das reuniões e mobiliza a participação dos demais profissionais. Nelas, constatamos a constante discussão sobre os processos de trabalho e sobre os modos do trabalho em equipe.

3) Ações de prevenção e promoção de saúde. Existem grupos de promoção de saúde desenvolvidos por cada ESF. Representantes do NASF se revezam na participação e programação dos grupos de: hipertensos, diabéticos, gestantes, adolescentes, idosos, cuidadores, pessoas em sofrimento psíquico, obesidade e grupo equilíbrio (realizado com os próprios profissionais de saúde, com ênfase na saúde do trabalhador). Alguns deles foram propostos e já existiam mesmo antes da implementação do NASF. Outros foram recuperados ou propostos pelo NASF,

\author{
(I) A escolha do NASF a \\ ser pesquisado foi \\ sugerida pela \\ coordenação dos NASF \\ de Maringá, por \\ considerá-lo um núcleo \\ consolidado e bem \\ articulado na rede. A \\ realidade de implantação \\ e implementação de cada \\ NASF nesse município \\ não é homogênia. Há \\ equipes que não foram \\ bem compreendidas e \\ sofrem resistência das \\ equipes de referência. \\ Há equipes que sofreram \\ problemas relacionados à \\ rotatividade de \\ profissionais. Há equipes \\ incompletas... As \\ pesquisadoras acataram a \\ sugestão da coordenação \\ por entenderem que, \\ para perceber as \\ possibilidades e desafios \\ de implementação dessa \\ proposta, é necessário \\ que a equipe não esteja \\ em um momento tão \\ incipiente de \\ implantação, já que isso \\ poderia supervalorizar os \\ desafios e dificultar a \\ percepção das \\ possibilidades do \\ programa.
}


(m) O APSUS é um Programa de Qualificação da Atenção Primária à Saúde, implementado, em 2012, no Paraná pela Secretaria Estadua de Saúde, voltado para desenvolvimento de un nova lógica para a organização da Atenção Primária à Saúde (APS), estreitando as relações entre o Estado e os Municípios, fortalecendo as capacidades de assistência e de gestão, com vistas à implantação das Redes de Atenção à Saúde (RAS) na implementação do SUS. mas todos são coordenados por profissionais da ESF. Também existem ações programáticas do calendário de saúde estabelecido pela Secretaria da Saúde, nas quais o NASF também se envolve na organização e participação das atividades, tais como: na semana de combate ao câncer do colo do útero, na semana de saúde do homens, na semana de saúde na escola... dentre outras.

4) Ações de Apoio Institucional. Em 2012, alguns profissionais desse e de outros NASF foram nomeados como Apoiadores Institucionais pela Portaria Municipal $\mathrm{n}^{\circ} 003^{31}$, visando: o desenvolvimento de ações para estruturação das redes temáticas, o apoio às equipes inscritas no Programa de Melhoria do Acesso e da Qualidade (PMAQ), e a implementação do Programa de Qualificação da Atenção Primária (APSUS) ${ }^{(m)}$. Tivemos a oportunidade de presenciar membros do NASF desenvolvendo a ação de apoio institucional para implementação do PMAQ em 2012 e a ação de apoio institucional na realização das oficinas de qualificação do APSUS em 2013. Neste ano, o APSUS teve como objetivo proporcionar que os participantes das oficinas desenvolvessem competência para implementar o gerenciamento dos processos de atenção à urgência e emergência aos cidadãos nas UBS, em busca da consolidação da Rede de Atenção à Urgência e Emergência no estado.

Em nosso entendimento, o apoio institucional, conforme definido pela $\mathrm{PNH}$, pode ser percebido não só neste último ponto, mas, também, nos demais, tendo em vista que, em todos eles, é possível perceber o NASF como uma unidade de produção que: coloca em análise os métodos de trabalho instituídos, incentiva trabalho cooperativo em equipe, estimula troca dos saberes, propõe a análise dos movimentos institucionais e a criação de processos de trabalho que não distanciem as atividades da gestão e da atenção.

Por isso, propusemos a utilização do termo "faces" da função apoio. Ao propormos a realização de apoio matricial e apoio à gestão, os arranjos organizacionais e os processos de trabalho modificaram-se e, sendo assim, o apoio institucional emerge no processo.

Analisamos o arranjo dado pela Secretaria de Saúde de Maringá, ao nomear profissionais do NASF como apoiadores institucionais, como um fenômeno que reconhece a possibilidade do exercício da face apoio institucional no NASF, embora as diretrizes e portarias não façam menção dessa possibilidade.

No entanto, não podemos deixar de mencionar que, na fala dos profissionais do NASF, há relatos de que esse arranjo acaba por prejudicar o exercício do apoio matricial, entendido por eles como sua principal função: “Este ano ainda não conseguimos retomar o trabalho do 'grupo equilíbrio', porque estamos muito envolvidos com as oficinas de APSUS. Isso atrasa o trabalho da gente" (entrevista realizada com profissional 2 do NASF). "No ano passado, o PMAQ consumiu bastante a gente e o grupo de cuidadores ficou deixando a desejar. Acaba que não conseguimos realizar nosso trabalho direito" (fala de um profissional do NASF - anotações do diário de campo das pesquisadoras). "A ação de matriciamento agora não está acontecendo muito porque estamos dedicados ao APSUS. Temos que apoiar as equipes no desenho do novo fluxograma. Mas depois, precisamos retomar nosso trabalho" (entrevista realizada com profissional 3 do NASF).

Diante disso, esse arranjo dado exige reflexão. Estariam estes profissionais sobrecarregados ao terem sido também designados para a função de apoio institucional? Ou a sensação de que eles não estariam cumprindo a função que Ihes cabe surge, exatamente, do fato de que as diretrizes e portarias não nominam o apoio institucional como função possível do NASF?

Sem a pretensão de encontrar respostas para estas questões e mais interessados em propor a discussão, esse trabalho se fez para incrementar o 
debate sobre a possibilidade de o NASF funcionar como estratégia de superação da lógica verticalizada, fragmentada, especializada e medicalizadora do cuidado e da gestão em saúde. Acreditamos que o NASF, apesar dos desafios existentes, apresenta-se como uma proposta interessante para cumprir a função apoio e fortalecer o desenvolvimento do SUS.

Entendemos que o NASF recupera o sentido etimológico da palavra apoio e, em analogia com a sua utilização original, apresenta-se como uma base alta que coloca, em evidência, a produção coletiva da saúde.

\section{Colaboradores}

Renata Heller de Moura e Cristina Amélia Luzio participaram, igualmente, de todas as etapas de elaboração do artigo.

\section{Referências}

1. Paim J. et al [internet]. O sistema de saúde brasileiro: história, avanços e desafios. 2011 [acesso 2013 abr 20]. Disponível em: http://download.thelancet.com/ flatcontentassets/pdfs/brazil/brazilpor1.pdf

2. Santos NR. Desenvolvimento do SUS: rumos estratégicos e estratégias para visualização dos rumos. Cienc Saude Colet. 2007; 12(2):429-35.

3. Oliveira GN. Devir apoiador: uma cartografia da função apoio [tese]. Campinas: Faculdade de Ciências Médicas, Universidade Estadual de Campinas; 2011.

4. Aciole GG. A saúde no Brasil: cartografias do público e do privado. São Paulo: Hucitec; 2006.

5. Coelho IB. Democracia sem equidade: um balanço da reforma sanitária e dos dezenove anos de implantação do Sistema Único de Saúde no Brasil. Cienc Saude Colet. 2010; 15(1):171-83.

6. Brasil. Portaria GM No154, de 24 de janeiro de 2008 [internet]. Cria os Núcleos de Apoio à Saúde da Família. 2008 [acesso 2011 Set 8]. Disponível em: http:// dab.saude.gov.br/docs/legislacao/poraria154_24_01_08.pdf

7. Campos GWS. Paideia e gestão: indicações metodológicas sobre o apoio. In: Campos GWS, organizador. Saúde Paidéia. São Paulo: Hucitec; 2007. p. 85-102.

8. Fernandes FD. (In)ventando multiplicidades: a função apoio enquanto dispositivo de produção de saúde no SUS [trabalho de conclusão de curso]. São Paulo: Faculdade de Medicina, Universidade de São Paulo; 2012.

9. Sampaio J. et al. O NASF como dispositivo da gestão: limites e possibilidades. Rev Bras Cienc Saude. 2012; 16(3):317-24.

10. Michaelis. Dicionário Escolar da Língua Portuguesa. São Paulo: Melhoramentos; 2009.

11. Campos GWS. O anti-Taylor: sobre a invenção de um método para co-governar instituições de saúde produzindo liberdade e compromisso. Cad Saude Publica. 1998; $14(4): 863-70$.

12. Cunha GT, Campos GWS. Apoio matricial e Atenção Primária em Saúde. Saude Soc. 2011; 20(4):961-70. 
13. Morais APP, Tanaka OY. Apoio matricial em saúde mental: alcances e limites na atenção básica. Saude Soc. 2012; 2(1):161-70.

14. Massuda A. O método do apoio Paidéia no Hospital: descrição e análise de uma experiência no HC [dissertação]. Campinas: Faculdade de Ciências Médicas, Universidade Estadual de Campinas; 2010.

15. Carvalho SR, Campos GWS. Modelos de atenção à saúde: a organização de Equipes de Referência na rede básica da Secretaria Municipal de Saúde de Betim, Minas Gerais. Cad Saude Publica. 2000; 16(2):507-15.

16. Ministério da Saúde. Secretaria-Executiva. Núcleo Técnico da Política Nacional de Humanização. HumanizaSUS: equipe de referência e apoio matricial. Brasília, DF: MS; 2004

17. Santos-Filho SB, Barros MEB, Gomes RS. A Política Nacional de Humanização como política que se faz no processo de trabalho em saúde. Interface (Botucatu). 2009; 13 Supl.1:603-13

18. Vasconcelos MFF, Morschel A. O apoio institucional e a produção de redes: do desassossego dos mapas vigentes na Saúde Coletiva. Interface (Botucatu). 2009; 13 Supl.1:729-38.

19. Mori ME, Oliveira OVM. Os coletivos da Política Nacional de Humanização (PNH): a cogestão em ato. Interface (Botucatu). 2009; 13 Supl. 1:627-40.

20. Heckert ALC, Neves CAB. Modos de formar e modos de intervir: quando a formação se faz potência de produção de coletivo. In: Brasil. Ministério da Saúde. Secretaria de Atenção à Saúde. Política Nacional de Humanização: formação e intervenção. Brasília, DF: MS; 2010. p. 13-28.

21. Ministério da Saúde. Secretaria de Atenção à Saúde. Política Nacional de Humanização: formação e intervenção. Brasília, DF: MS; 2010a.

22. Ministério da Saúde. Secretaria-Executiva. Caderno de referência para o processo de formação de profissionais do Apoio Institucional Integrado do Ministério da Saúde: QUALISUS-REDE. Brasília, DF: MS; 2011.

23. Ministério da Saúde. Secretaria de Atenção à Saúde. Departamento de Atenção Básica. Caderno de Diretrizes do NASF. Brasília, DF: MS; 2009.

24. Ministério da Saúde. Secretaria de Atenção à Saúde. Departamento de Atenção Básica. Oficina de qualificação do NASF. Brasília, DF: MS; $2010 \mathrm{~b}$.

25. Brasil. Portaria no 3.124, de 28 de dezembro de 2012 [internet]. Redefine os parâmetros de vinculação dos Núcleos de Apoio à Saúde da Família (NASF). 2012 [acesso 2012 Set 8]. Disponível em: http://bvsms.saude.gov.br/bvs/saudelegis/gm/ 2012/prt3124_28_12_2012.html

26. Garcia Junior CAS, Nascimento PTA. O dispositivo apoio matricial na atenção primária em saúde: um relato de experiência no município de João Pessoa/PB. Rev Saude Publica Santa Catarina. 2012; 5(2):93-104.

27. Menezes CA. Implantação do Núcleo de Apoio ao Programa de Saúde da Família (NASF) em Olinda: estudo de caso [dissertação]. Rio de Janeiro: Centro de Pesquisa Aggeu Magalhães, Fundação Oswaldo Cruz; 2011.

28. CNES.Cadastro Nacional de Estabelecimentos de Saúde [internet]. Sistema de Informações da Atenção Básica. 2013 [acesso 2012 Set 8]. Disponível em: cnes.datasus.gov.br

29. IBGE. Pesquisa Nacional por Amostra de Domicílios. Rio de Janeiro: Ministério do Planejamento e Orçamento; 2010. 
O APOIO INSTITUCIONAL COMO UMA DAS FACES ...

30. Secretaria de Saúde de Maringá [internet]. Plano municipal de saúde 2010-2013. Programa Maringá Saudável. Maringá, 2010 [acesso 2013 Abr 4]. Disponível em: http://www2.maringa.pr.gov.br/sistema/arquivos/edca39be41b9.pdf

31. Maringá. Portaria $n^{\circ}$ 003/2012. Dispõe sobre a composição da Comissão de Apoio Institucional da Secretaria Municipal de Saúde. Maringá: Secretaria Municipal de Saúde; 2012.

Moura RH, Luzio CA. El apoyo institucional como uno de los aspectos de la función de apoyo en el Núcleo de Apoyo a la Salud de la Familia (NASF). Interface (Botucatu). 2014; 18 Supl 1:957-70.

El objetivo de este trabajo es aumentar el debate sobre el NASF, a partir de una reflexión sobre la función de apoyo. Por lo general, tal función se presenta en los documentos del Ministerio de Salud y en las publicaciones académicas y científicas, acompañada de descripciones que la caracterizan. Solemos encontrar diferentes tecnologías, como: "apoyo institucional", "apoyo a la gestión", "apoyo matricial". En relación al NASF, las publicaciones examinadas destacan la característica central del desempeño del apoyo matricial. Sin embargo, nos preguntamos: ¿cuáles son los aspectos que la función de apoyo ha tenido en la implementación de este programa? Para reflexionar sobre esa y otras cuestiones, hemos desarrollado un estudio de carácter cualitativo en un equipo del NASF, en el interior del Estado de Paraná, utilizando las herramientas metodológicas: observación participativa, entrevistas semiestructuradas y grupos de discusión. Buscamos demostrar que la dinámica de la función de apoyo en el NASF permite el surgimiento tanto del apoyo matricial como del institucional.

Palabras clave: Apoyo institucional. Apoyo matricial. Núcleo de Apoyo a la Salud de la Familia. Atención Básica de la Salud. Salud Pública.

Recebido em 20/05/13. Aprovado em 20/07/13 